\title{
Modelling of Hybrid Wind and Solar System Using Multi Stage Convertors with the Help of MATLAB SIMULINK
}

\author{
Neha R. Khanzode, Sachin Gour
}

\begin{abstract}
The aim of this study is to introduce the local PV-wind hybrid system's working principle by reviewing one case where the system is connected to the grid. The thermal power stations are causing pollution which severely affects mankind and nature. These power stations result in causing many diseases. Also natural resources like coal, oil,radioactive materials etc will get extinct in near future. The other existing power generating systems like Hydro-Electricity power generating plant cannot afford much power as it is season based, although it causes less pollution. Therefore, it is of great urgency to go for non conventional energy resources. In recent years, environmental friendly technological solutions are becoming more prominent as a result of concern over the state of our deteriorating planet. The main purpose of this hybrid wind-solar energy system is to meet our daily demand effectively and to get an uninterrupted power supply from any one of the natural source either wind or solar or both. The hybrid model is designed using CukSEPIC fused convertors and the performances are analyzed. Due to the inherent nature of this Cuk-SEPIC fused convertors, we get optimum efficiency Simulation results are given to highlight the merits of the proposed circuit. To ful fill the challenging demands of the growing grid, new concepts of the inverters are needed. Inthis project a reduced switch modular inverter design is detailed. A modular inverter design is presented for a modern power system which inputs power from both AC andDC Renewable Sources.
\end{abstract}

Keywords: Hybrid System, multi winding transformer, cuk-sepic convertors, modular inverter; MATLAB/SIMULINK

\section{INTRODUCTION}

The integration of renewable energies such as solar and wind [1][2]energy is becoming increasingly attractive and is being used widely, for substitution of oil-produced energy, and eventually to minimize atmospheric degradation. In the recent years, photo voltaic power generation has been receiving considerable attention as one of the more promising energy alternative. The reason for this rising interest lies in the direct conversion of sunlight into electricity. Photo voltaic energy conversion is one of the most attractive non conventional energy sources of proven reliability from the micro to mega watt level. Its advantages are:

1. Absence of moving part

2. Ability to function unattended for long periods .

3. Modular nature in which desired current, voltage and power level can be obtained by mere integration

4. Long effective life and high reliability

Combined wind and solar systems are becoming more popular for stand-alone power generation applications, due to advances in renewable energy technologies and subsequent rise in prices of petroleum products. Before building a system with several intermittent energy sources and variable consumption, guidance on the dimensioning of the individual components should be obtained by simulating the system operation under the local conditions, including as appropriate the weather, insulation, wind etc. In general a key objective of such systems is to use the maximum proportion of renewable energy[3][4], but other factors including the financial investment, social aspects, local infrastructure, durability etc. must also be considered. The components and subsystems of a standalone system based on renewable sources are interconnected to optimize the whole system. The design of a hybrid system will depend on the requirements of the user (isolated or not isolated location, rural or urban, DC or AC supply), and on the power supply system. Usually, most of hybrid systems are designed to supply electric power for lighting fixtures, radio/TV, domestic appliances, submersible water pumps etc. This is typical in isolated areas for rural households as well as of some public buildings such as schools, cultural establishments, etc In Kenya, most of the solar/wind hybrid energy systems available are used for small scale power production. In the case of a larger demand or large scale application e.g. for inclusion into the main power grid a third energy source is used as a back up and in most cases it is a diesel generator.

\section{BASIC COMPONENTS OF A SMALL HYBRID SYSTEM}

A typical small hybrid power system [5],[6] can contain the following components:

Solar PV Generator: containing a number of series/parallel interconnected solar modules (depending on the necessary voltage), including connection and protection elements (bypass diodes and/or anti-return). 
This element delivers part of the electric energy supply through solar energy conversion.

Wind generator: providing part of the necessary electric energy by converting the mechanical energy from the wind.

Storage unit (accumulator battery set): Usually $\mathrm{Pb}, \mathrm{Ni}-$ Cad or Ni-Fe batteries dedicated to applications in the area of renewable energy sources.

Unit for power conditioning: This can be a DC/DC converter (for DC loads) and/or inverters (for AC loads) depending on the load to be used.

\section{STUDY AREA}

\section{Wind power in India}

The development of wind power in India began in the 1990s, and has significantly increased in the last few years. Although a relative newcomer to the wind industry compared with Denmark or the United States, India has the fifth largest installed wind power capacity in the world. In 2009-10 India's growth rate was highest among the other top four countries.

Table 1. Wind production Capacity of States

\begin{tabular}{|c|c|}
\hline State & Capacity (in MW) in 2014 \\
\hline Tamilnadu & 7253 \\
\hline Gujrat & 3414 \\
\hline Maharashtra & 2976 \\
\hline Rajsthan & 2820 \\
\hline Karnataka & 2409 \\
\hline Andhra Pradesh & 753 \\
\hline Madhya Pradesh & 439 \\
\hline Kerala & 55 \\
\hline Others & 4.3 \\
\hline Total & $\mathbf{2 1 2 6 4}$ \\
\hline
\end{tabular}

It is estimated that $6,000 \mathrm{MW}$ of additional wind power capacity will be installed in India by 2014 . Wind power accounts for $8.5 \%$ of India's total installed power capacity, and it generates $1.6 \%$ of the country's power. The worldwide installed capacity of wind power reached 283 GW by the end of 2012. China (75,564 MW), US (60,007 MW), Germany (31,332 MW) and Spain (22,796 MW) are ahead of India in fifth position. The short gestation periods for installing wind turbines, and the increasing reliability and performance of wind energy machines has made wind power a favoured choice for capacity addition in India.

\section{Solar power in India}

India is densely populated and has high solar isolation, an ideal combination for using solar power in India. In the solar energy sector, some large projects have been proposed, and a $35,000 \mathrm{~km} 2(14,000 \mathrm{sq} \mathrm{mi})$ area of the Thar Desert has been set aside for solar power projects, sufficient to generate 700 to 2,100 GW. In July 2009, India unveiled a US $\$ 19$ billion plan to produce $20 \mathrm{GW}$ of solar power by 2020 .

On 16 May 2011, India's first 5 MW of installed capacity solar power project was registered under the Clean Development Mechanism. The project is in Sivagangai Village, Sivaganga district, Tamil Nadu.

Table 2. Solar power production capacity of states

\begin{tabular}{|c|c|c|}
\hline State & Power in MW & Power in \% \\
\hline Andhra Pradesh & 41.75 & 3.18 \\
\hline Chhattisghrh & 4 & 0.3 \\
\hline New Delhi & 2.5 & 0.19 \\
\hline Gujrat & 654.8 & 49.9 \\
\hline Haryana & 7.8 & 0.59 \\
\hline Jharkhand & 4 & 0.3 \\
\hline Karnataka & 9 & 0.69 \\
\hline Madhya Pradesh & 132 & 9.15 \\
\hline Maharashtra & 20 & 1.38 \\
\hline Odisha & 13 & 0.99 \\
\hline Punjab & 9 & 0.69 \\
\hline Rajasthan & 510.25 & 38.89 \\
\hline Tamil Nadu & 15 & 1.14 \\
\hline Uttar Pradesh & 12 & 0.91 \\
\hline Uttarakhand & 5 & 0.38 \\
\hline West Bengal & 2 & 0.15 \\
\hline Total & $\mathbf{1 4 4 2 . 1}$ & $\mathbf{1 0 0}$ \\
\hline
\end{tabular}

With about 300 clear, sunny days in a year, India's theoretical solar power reception, on only its land area, is about 5,000 trillion kilowatt-hours $(\mathrm{kWh})$ per year (or 5 $\mathrm{EWh} / \mathrm{yr}$ ). The daily average solar energy incident over India varies from 4 to $7 \mathrm{kWh} / \mathrm{m} 2$ with about 1,500-2,000 sunshine hours per year (depending upon location), which is far more than current total energy consumption.

\section{MATHEMATICAL MODELLING OF A SOLAR CELL}

The mathematical modelling describing the figure 1 andfigure 2 of a solar cell is given as Let

Iph is photon generated current (A)

I is Load current (A)

Id is diode current $(\mathrm{A})$

Isat is saturation current of Diode (A)

$\mathrm{V}$ is Forward Voltage (V)

$\mathrm{q}$ is electron Charge (1.60217646 e-19 Coulomb) 


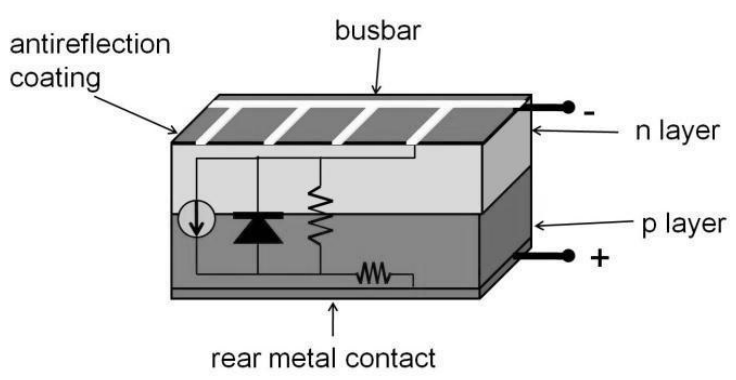

Figure 1. PV module configurations in a PV plant

A is diode ideality factor (1)

$\mathrm{K}$ is Boltzmann constant $(1.3806503 \mathrm{e}-23 \mathrm{~J} / \mathrm{K})$

VT is the diode thermal voltage

$\mathrm{S}$ is solar irradiation (Watt per square meters)

$\mathrm{T}$ is Temperature [Kelvin]

RS is Series resistance $(\Omega)$

$\mathrm{RP}$ is Shunt resistance $(\Omega)$

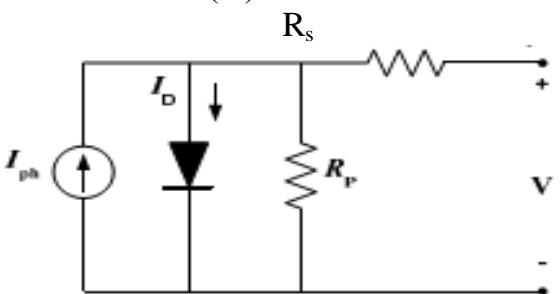

Figure 2. Equivalent circuit of a Solar cell

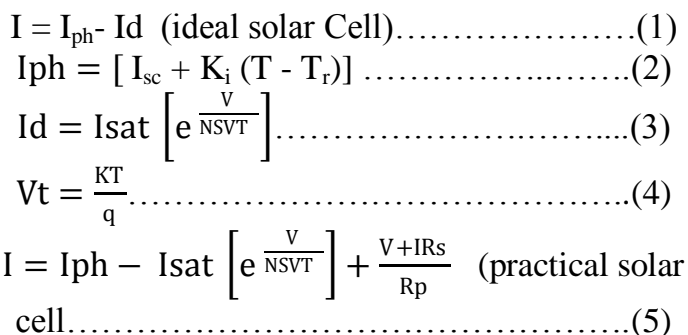

The equation for a single diode equivalent equation for a solarcell under illumination is given in equation (2).Using solar cell equations (1), (2) and (3), model of PVmodule[7],[8],[9] is built in Simulink. The model of a solar cell isshown in Figure 2 which is coded to obtain a PV module.

\section{Solar modules and Arrays}
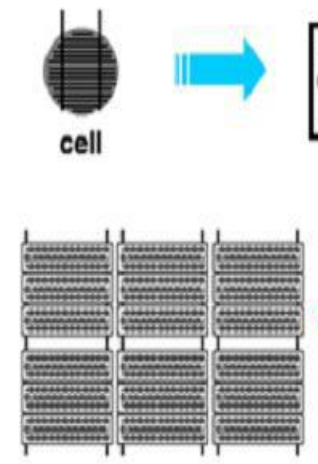

Figure 3. Photovoltaic cell, module, arrays and panels
Due to the low voltage of an individual solar cell (typically $0.5-0.6 \mathrm{~V}$ ), several cells are wired in series in the manufacture of a "laminate". The laminate is assembled into a protective weatherproof enclosure, thus making a photovoltaicmodule or solar panel. Modules may then be strung together into a photovoltaicarray.

\section{THE PROPOSED MULTISTAGE CONVERTER} STAGE

A system diagram as shown in Fig 6, where one of the inputs is connected to the output of the PV array and other inputs is connected to the output of the generator output. The fusion of the two converters is achieved by reconfiguring the two existing diodes from each converter and the shared utilization of the cuk [10] [11], [12], [13] output inductor by the sepic converter[11],[13],[14] together become a proposed rectifier stage of the hybrid energy system[13],[15],[16],[17]. This configuration allows each converter to operate normally individually in the event that one source is unavailable. Fig. 7 illustrates the case when onlythe wind source is available. In this case, D1 turns off and D2 turns on; the proposed circuit becomes a sepic converter. On the other hand, if only the PV source is available, then D2 turns off and D1will be always on and circuit becomes a cuk converter as shown in Fig. 8. In both cases, both the converters have step up/down capability, which provides more design flexibility in thesystem if the duty ratio control is utilized.

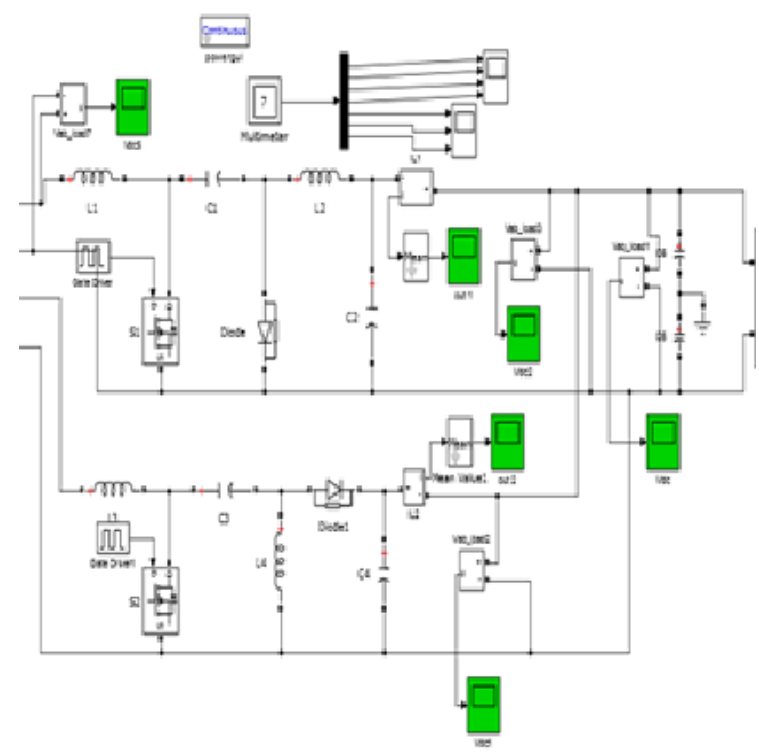

Figure 6.cuk sepic based converter on source side

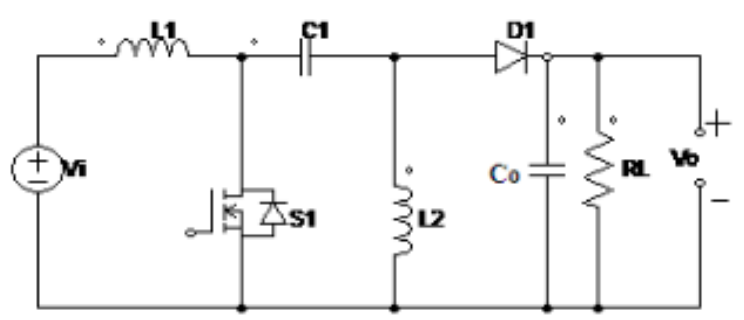

Figure 7. Sepic Converter 


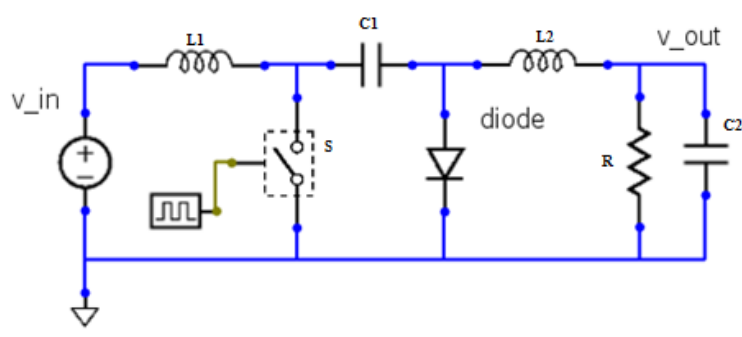

Figure 8.Cuk Converter

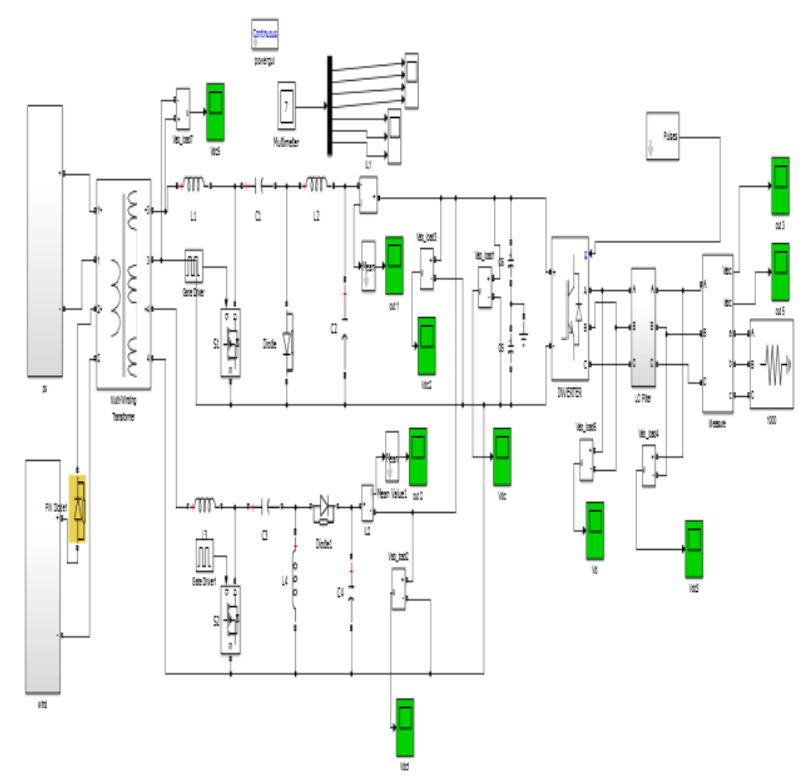

Figure9. Cuk- Sepic proposed model

\section{DESIGN OF MULTIPLE WINDING TRANSFORMER}

A multiple winding Transformer can be defined as the one which has more than one primary or secondary windings connected to each other in some special type of configuration in order to provide the required output voltage levels or drive a number of loads at the output.

This can be referred to as one special characteristic of the transformer, as transformers are quite versatile devices and usually much advanced operations need to be accomplished with them rather than driving merely one output from a single primary coil.

Multiple Winding Transformers are also known as "Multiple Coil Transformers" or "Multi Wound Transformers".

The operating principle of a multiple winding transformer is exactly similar to that of a simple transformer having one primary winding and providing magnetic flux to its one and only secondary coil at the output. If there is more than one coil at the input terminal, all of them will be given the alternating source voltage in the similar fashion, and would be linked through one and the same iron core to the two or more secondary coils at the output. In this way, an alternating magnetic flux would also be produced in all of the secondary coils, which mostly is equal in magnitude, and the voltage can also be obtained according to the requirements. For example, a multi wound step uptransformer can be made, and so a step down transformer also.

If we want to drive more than one output, i.e. if we have a number of loads, then the transformer can still be connected such that secondary winding is divided into number sub windings, each driving an independent load at its ends.

The thing that should be noted here is that, since all the coils primary are connected through a common iron core to their secondary coils, so due to Faraday's Law of Mutual Induction, each individual sub coil would have the same number of voltage per turn, that is, its ratio of primary turns to secondary would still be equal to the ratio of primary voltage to secondary voltage, as for a usual transformer.

$$
\frac{\mathrm{N}_{\mathrm{p}}}{\mathrm{N}_{\mathrm{s}}}=\frac{\mathrm{V}_{\mathrm{p}}}{\mathrm{V}_{\mathrm{s}}} \ldots \ldots \ldots .
$$

So each secondary coil produces the amount of voltage which is directly proportional to its number of turns, since all the coils are electrically isolated and magnetically linked to each other, and to the primary coil as well.

As in the above figure, the two individual primary coils can be connected in series with each other to give a higher primary supply voltage, or the same thing can be done at the other end by connecting the two separate secondary windings in series with each other to achieve a higher supply voltage at the output instead of two individual small voltages. SuchConnections will be known as Series connections of the windings. Similarly, the two or more windings can be connected in Parallel as well to achieve lower voltages but higher currents, as we know that the voltage remains the same in parallel, but the current adds up. Other than these two configurations, the coils can be used as they are in the above figure to drive two individual circuit.The beauty of transformers is that they allow us to have more than just one winding in either the primary or secondary side. Transformers which have more than one winding are known commonly as Multiple Winding Transformers.

The principal of operation of a multiple winding transformer is no different from that of an ordinary transformer. Primary and secondary voltages, currents and turns ratios are all calculated the same, the difference this time is that we need to pay special attention to the voltage polarities of each coil winding, the dot convention marking the positive (or negative) polarity of the winding, when we connect them together.

Multiple winding transformers, also known as a multi-coil, or multi-winding transformer, contain more than one primary or more than one secondary coil, hence their name, on a common laminated core. They can be either a single-phase transformer or a three-phase transformer, (multi-winding, multi-phase transformer) the operation is the same.

Multiple Winding Transformers can also be used to provide either a step-up, a step-down, or a combination of both between the various windings. In fact a multiple 
winding transformers can have several secondary windings on the same core with each one providing a different voltage or current level output.

As transformers operate on the principal of mutual induction, each individual winding of a multiple winding transformer supports the same number of volts per turn, therefore the volt-ampere product in each winding is the same, that is

$$
\frac{\mathrm{N}_{\mathrm{p}}}{\mathrm{N}_{\mathrm{s}}}=\frac{\mathrm{V}_{\mathrm{p}}}{\mathrm{V}_{\mathrm{s}}} \ldots \ldots \ldots
$$

with any turns ratio between the individual coil windings being relative to the primary supply.

In electronic circuits, one transformer is often used to supply a variety of lower voltage levels for different components in the electronic circuitry. A typical application of multiple winding transformers is in power supplies and triac switching converters. So a transformer may have a number of different secondary windings, each of which is electrically isolated from the others, just as it is electrically isolated from the primary. Then each of the secondary coils will produce a voltage that is proportional to its number of coil turns for example fig. 10 shows a typical "multiple winding transformer" which has a number of different secondary windings supplying various voltage levels. The primary windings can be used individually or connected together to operate the transformer from a higher supply voltages.

The secondary windings can be connected together in various configurations producing a higher voltage or current supply. It must be noted that connecting together in parallel transformer windings is only possible if the two windings are electrically identical. That is their current and voltage ratings are the same.

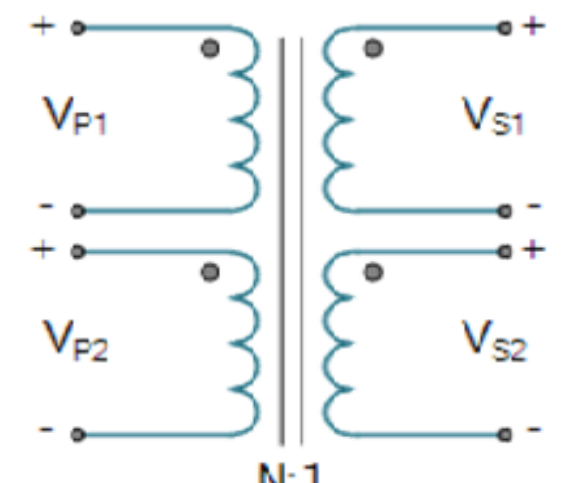

$\mathrm{N}: 1$

Figure10. Multiple Winding Transformer

\section{DESIGN OF MODULAR INVERTER WITH REDUCED SWITCH}

Signification

Conventional three phase inverter system structures are fixed in size and function and offer only limited flexibility demands and to be more versatile in production and development, a new standardized system concept with modular structure is needed. Modularity basically means a segmentation of the complex structures into functional groups. In this way the main components of an inverter[16] structure can be subdivided and the resulting modules can be treated as standalone systems. By use of standardized interfaces these separated modules can be scaled independently. The result is an inverter system that is completely adaptive regarding size, components, configuration and the operating control. The system is flexible to be quickly adapted and optimized for any application demands. Modularity[17],[18],[19] or modular design is the subdivision of a complex system into smaller units (modules) with basic functionalities. These modules can then be used in different systems with multiple functionalities. A module pool keeps different discrete modules that can perform defined discrete tasks or functions. To connect any modules in a free selectable order and topology, standardized interfaces have to be defined to react on linked neighbor modules and hand over information to them. Production costs are reduced by completely independent manufacturing of the various modules. Furthermore, modular design offers additional benefits such as augmentation and exclusion. An existing system can be enlarged, updated, modified or pared down in functionality by adding or excluding new sub functional modules.

\section{Principle to Design Modular Inverter}

The basic principle of modularity can be applied to the two main fields of inverter design, the hardware and the software design. Although these design fields are functional closely underlying project, the modular approach has been applied to the design of an exemplary inverter system the applied modularity will now be detailed. At this point it has to be mentioned that the level and depth of modular design applied to inverters, but also to any other system, always depends on the product range of the manufacturer and the applications to be covered by the designed systems. The more complex a system is and the more functions it has to perform, the higher the level of modularity should be. The characteristic of the inverter load regarding the symmetry is one of the main influencing factors of the desired power electronic inverter topology. with neutral point.

Three main module pools can be built. These are the converter, the intermediate circuit and the switch topology module pool. By selection of modules from these three module pools any typical basic inverter topology can be set up in hardware. The converter module pool itself contains DC/DC converters to adjust the voltage level of DC ECS to the intermediate circuit voltage and to actively control the DC sources. Passive and active rectifiers of this pool are able to connect AC sources to the intermediate circuit.

The intermediate circuit pool keeps two different module types the circuits are the standard two level intermediate circuits built by one capacitor and the three level intermediate circuits with divide the intermediate circuit voltage in halves by the use of two series capacitors. 


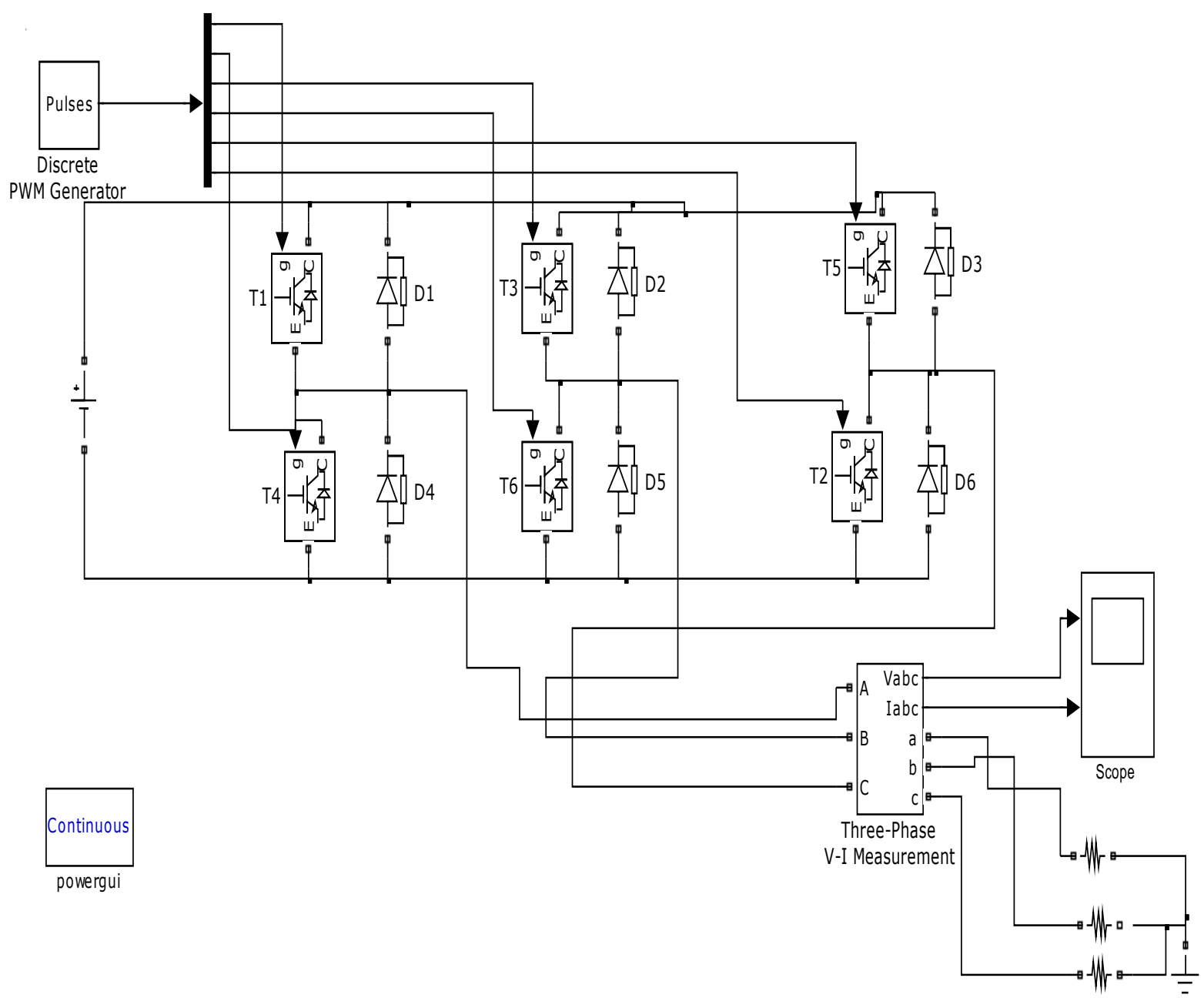

Figure 11.Inverter Model

The third wire in this case is connected to midpoint between the two capacitors. A chopper circuit is available for all intermediate circuit modules. It is closely linked to the intermediate circuit and will not be treated as separated module because of security aspects. The inverter topology for symmetrical loads is this basic inverter is built of two MOSFET legs and with one split capacitor legs either three leg inverter or three leg inverter

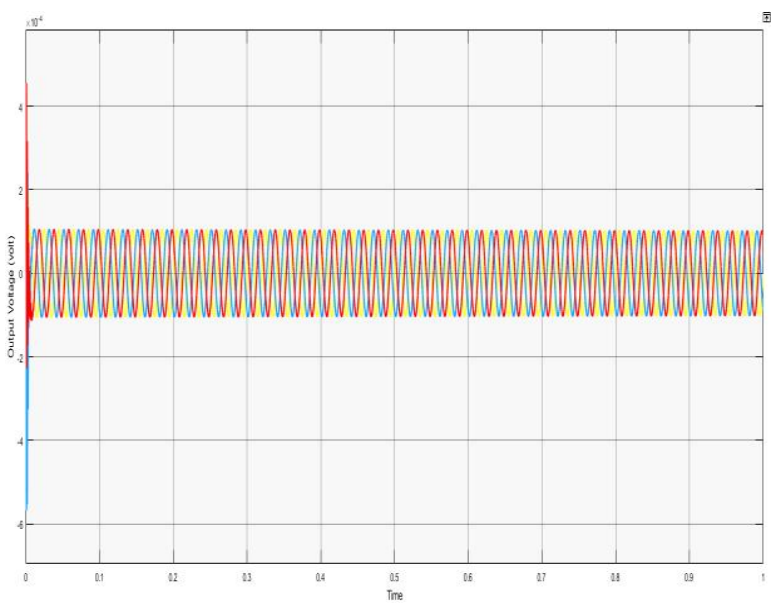

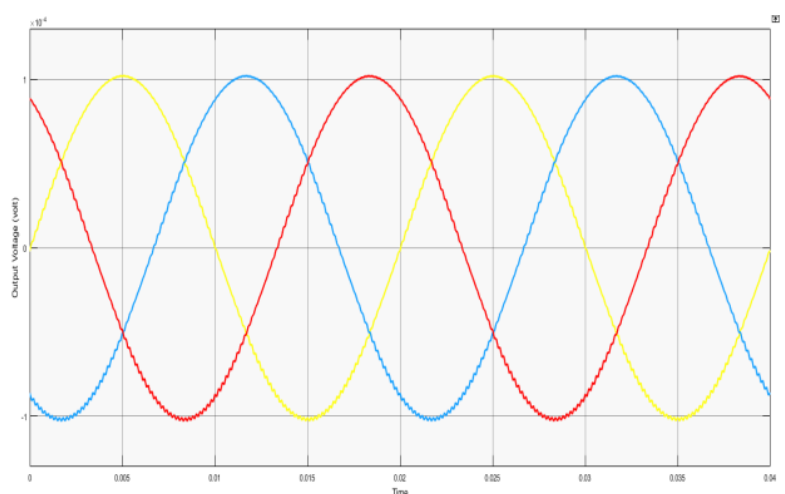

Figure 12.(a)Uninterrupted output voltage waveform (b) Zoom

\section{CONCLUSION}

Cuk - Sepic converter design methodology based modular inverter were proposed. Hence it is clear from the simulation results by reducing the number of switches in the modular inverter; it is able to get a desired simulation output as shown in simulation results, Due to the design of Cuk-SEPIC converter there is no need for additional Filter components in the proposed circuit; the features of the 
proposed system are (1) possible to work on both or any one of the renewable sources; (2) reducing the switches in the inverter side will leads to improve performance and efficiency; (3) so conduction losses and switching losses will had been reduced; (4) size of the component and cost are reduced. CUK - SEPIC Converter and modular inverter performance for the proposed system is analyzed through MATLAB software simulations.
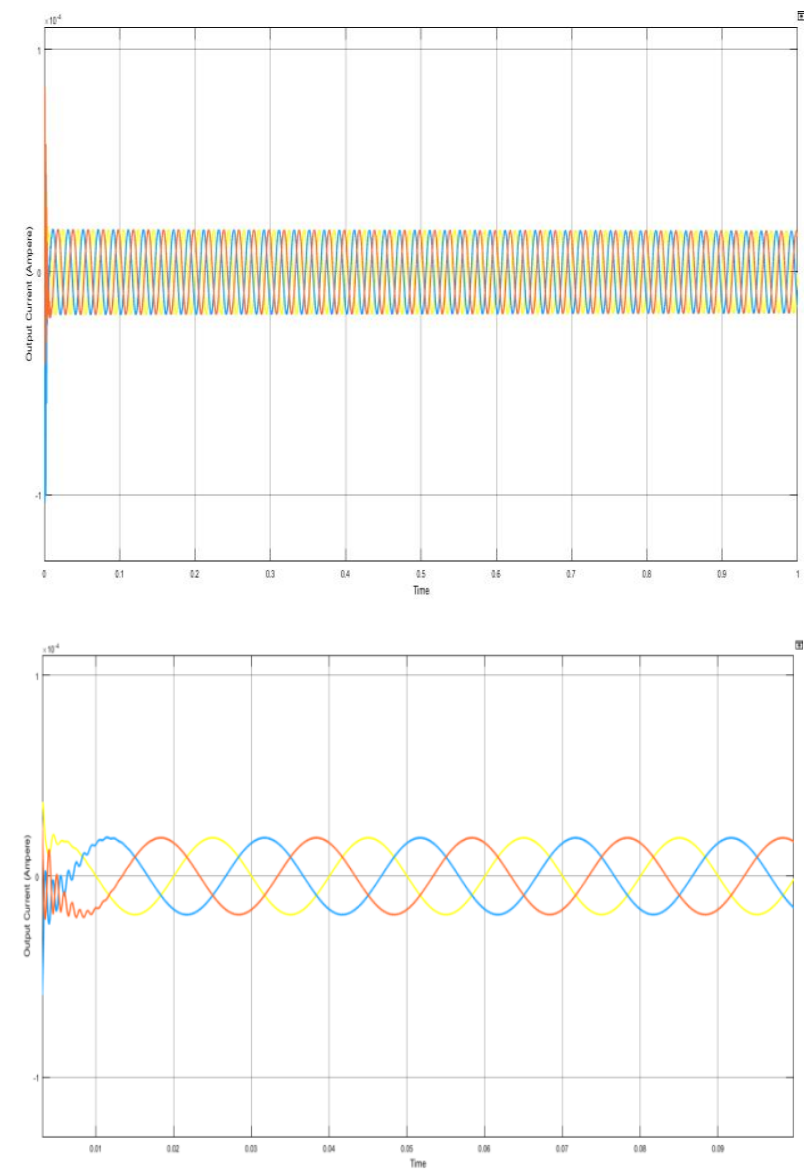

Figure 13.(a)Uninterrupted output Current waveform(b)Zoom

\section{REFERENCES}

[1] J.Teja, G.Ramakrishna Vagga,Sk.Jan Basha "A Hybrid Wind-Solar Energy System using Double-port Interface in a Micro grid" , International Journal of Emerging Trends in Electrical and Electronics (IJETEE) - ISSN: 2320 - 9569) Vol. 10, Issue. 9, Oct. 2014

[2] S.Angelin, Dr.V.Manikandan "Optimal Operation of Power in Renewable Energy by Usingprediction in Recurrent Neural Network",International Journal of Innovative Research in Computer and Communication Engineering,(An ISO 3297: 2007 Certified Organization)Vol. 2, Special Issue 3, July 2014

[3] Neeraj tiwari and bhagwan das "MPPT controller for photo voltaic systems using Cuk DC/DC convertor", International Journal of Advanced Technology \& Engineering Research (IJATER) ISSN NO: 2250-3536 volume 2, issue 2, may 2012

[4] Telmo de Sousa Lima "MPPT for Integrated a PV Micro-Inverter"

[5] Yuvaraj V, Roger Rozario, S.N. Deepa "Implementation And control of Multi - Input Power Converter for Grid Connected Hybrid Renewable Energy Generation System" student pulse june 2011 vol. 3 , issue 6
[6] Yu-Lin Juan and Hsin-Ying Yang, Peng-Lai Chen "An Isolated Dual-Input Converter for Grid/PV Hybrid Power Systems", journal of computers, vol. 8, no. 6, june 2013

7] Sheng-Yu Tseng and Cheng-Tao Tsai “ PV Power System with an Interleaving Boost Converter for Battery Charger Applications a PV (PV) power system for battery charger applications", Hindawi Publishing Corporation International Journal of Photoenergy, Volume 2012, doi:10.1155/2012/936843

[8] Huai wang, frede blaabjerg, ke ma and rui wu "Design for reliability in power electronics in renewable energy systems - status and future"

[9] M. F. Almi , m. Arrouf, h.belmili, s. Boulouma, b. Bendib ower “ Energy management of wind/pv and battery hybrid system", international journal of new computer architectures and their applications (ijncaa) 4(1): 30-38 the society of digital information and wireless communications, 2014 (issn: 2220-9085)

[10] Chitesh dubey, yogesh tiwari "To design solar (PV) - wind hybrid power generation system" international journal of emerging trends \& technology in computer science (ijettcs) volume 1 , issue 4 , november - december 2012 issn 2278-6856

[11] Divya teja reddy challa and raghavender inguva "An inverter fed with combined wind-solar energy system using Cuk-SEPIC converter" ,international journal of engineering research \& technology (ijert) vol. 1 issue 9, november- 2012 issn: 2278-0181

[12] K.kavitha and dr. Ebenezer jeyakumar "A synchronous Cuk converter based PV energy system design and simulation", international journal of scientific and research publications, volume 2, issue 10, october 2012 issn 2250-3153

[13] Aleksandar Radi, S.M. Ahssanuzzaman, Behzad Mahdavikhah, and Aleksandar Prodi "High-Power Density Hybrid Converter Topologies for Low-Power Dc-Dc SMPS", The 2014 International Power Electronics Conference 978-1-4799-2705-0/14/ ( 2014 IEEE

[14] Dr. Ray Ridley "Analyzing the SEPIC Converter" Power Systems Design Europe November 2006

[15] Vani Navasare and Prof.Raju Yanamshetti "Voltage Regulation Of Hybrid Wind-Solar Energy System” ,Journal of Multidisciplinary Engineering Science and Technology (JMEST) ISSN: 3159-0040 Vol. 1 Issue 4, November - 2014

[16] V. Saranya, M. Rekha, N. Gokulnath "Performance of Bidirectional Chopper and Multi- Operational Inverter with Hybrid Energy System", International Journal of Emerging Science and Engineering (IJESE) ISSN: 2319-6378, Volume-2 Issue-11, September 2014

[17] P. J. van Duijsen "Modeling Grid Connection for Solar and Wind Energy"

[18] E. M. Natsheh, A. Albarbar and J. Yazdani "Modeling and Control for Smart Grid Integration of Solar/Wind Energy Conversion System"

[19] Shen Lu , Nathan B. Schroeder, Harrison M. Kim, Uday V. Shanbhag "Hybrid Power/Energy Generation Through Multidisciplinary and Multilevel Design Optimization With Complementarily Constraints" Journal of Mechanical Design OCTOBER 2010, Vol. 132 / 101007-1 